\title{
Relations between Post-Mortem Alterations and Glycolytic Metabolism in the Brain
}

\author{
Reinhard L. Friede and Wiecher H. van Houten \\ Mental Health Research Institute, University of Michigan, Ann Arbor, Michigan
}

Received May 29, 1961

\begin{abstract}
Certain post-mortem alterations of brain tissue result from the continuation of anaerobic glycolysis in the presence of abolished tissue oxidation. Experimental incubation of cerebellar tissue from rats in glucose or in glucose-6-phosphate in the presence of cyanide resulted in klasmatodendrosis of astrocytes and marked edematous changes, particularly in the neuroglia of the Purkinje layer. The presence of glycolysis was indicated by a drop in $\mathrm{pH}$ of the incubation medium. The tissue changes were indistinguishable from post-mortem alterations in human material. Blocking of glycolysis during the incubation eliminated the experimental tissue changes. The distribution of post-mortem changes depended on the normal cytochemical organization of a given region; regions which normally showed large aggregations of neuroglia cells with weak activity of oxidative enzymes showed strongest glycolytic tissue alterations. There was exidently no sharp border line between normal tissue glycolysis and post-mortem alterations.
\end{abstract}

\section{Introduction}

With the cessation of blood circulation at death, the tissues become anoxic and the aerobic metabolism is abolished. Anaerobic glycolysis, however, may carry on for some time, depending on the carbohydrate reserves in the tissue; the acidity increases rapidly due to the formation of lactic acid $(4,6)$. The present study demonstrates that post-mortem continuation of anaerobic glycolysis in brain tissue caused certain characteristic tissue alterations; their distribution was intimately related to the normal cytochemical organization of a given region.

\section{Materials and Methods}

Rats were killed by a blow to the neck and the brain was removed as quickly as possible. Mechanical damage of the brain, such as pressure or tearing, was carefully avoided. Slices from the cerebellum or from other regions were cut $1 \mathrm{~mm}$ thick with a thin razor blade. They were incubated at $36^{\circ} \mathrm{C}$ in media containing 0 to $200 \mathrm{mg}$ glucose or glucose-6- 
phosphate per $100 \mathrm{ml}$ of solution, with or without the addition of glycolytic blockers ( $0.1 M$ sodium fluoride, sodium bisulfite, and iodomonoacetic acid); $0.005 M \mathrm{KCN}$ was always added to produce anoxibiotic conditions. The incubation period ranged from 1 to 4 hours and the $\mathrm{pH}$ of the medium was measured before and at the end of the incubation. The incubation was terminated by fixation of the specimens in Carnoy's solution. The tissue was embedded in paraffin and stained with hematoxylin and eosin or with periodic acid-Schiff, counterstained by chromalum gallocyanin. Other specimens were fixed in Cajal's solution and stained with Hortega's silver carbonate technique for astrocytes. Forty-four experiments will be reported.

\section{Results}

Glucose. Specimens incubated in glucose media showed maximal tissue alterations in the layer of Purkinje cells, particularly in the dense aggregations of neuroglia cells between the perikarya of the Purkinje cells (Fig. 1A). These neuroglia cells were markedly swollen, edematous, or ballooned, forming large vesicles; the nucleus and sparse remnants of cytoplasm were isolated in the center. At progressed stages, the cells were disrupted and the tissue continuity destroyed; the molecular layer was separated from the granular layer as if it had been forced off. The Purkinje cells appeared rather shrunken, contrary to the excessive swelling of the neuroglia cells. Swollen neuroglia cells were also found in the molecular layer of the cerebellar cortex, in the white matter, and in other regions of the brain. Their nuclei were often, but not consistently, shrunken.

Similar but much less developed changes were seen following incubation in balanced solution without glucose; these changes were attributed to the carbohydrate reserves of the tissue. The extent of the changes increased with increasing concentration of glucose in the medium (up to $200 \mathrm{mg} / 100 \mathrm{ml}$ ) and with the length of the incubation period (up to 4 hours). The $\mathrm{pH}$ of the medium dropped markedly during incubation.

None of the above tissue alterations were seen after incubation in glucose with the addition of glycolytic blockers (sodium fluoride, sodium bisulfite, iodomonoacetic acid). If the concentration of the blockers was too low, slight tissue alterations occurred in the central portion of the specimens which were not immediately exposed to the medium. If sufficient concentrations of blockers $(0.1 M)$ were used, there was neither glial swelling nor distortion of the tissue structure. Even after several 
hours of incubation the tissue structure was perfectly preserved, resembling that in brains fixed by perfusion immediately after death (Fig. 1B). Likewise, the $\mathrm{pH}$ of the medium did not drop.

Glucose-6-Phosphate. Following incubation in glucose-6-phosphate there were changes in the layer of Purkinje cells similar to those observed with glucose. In addition to these changes there was a marked swelling of the

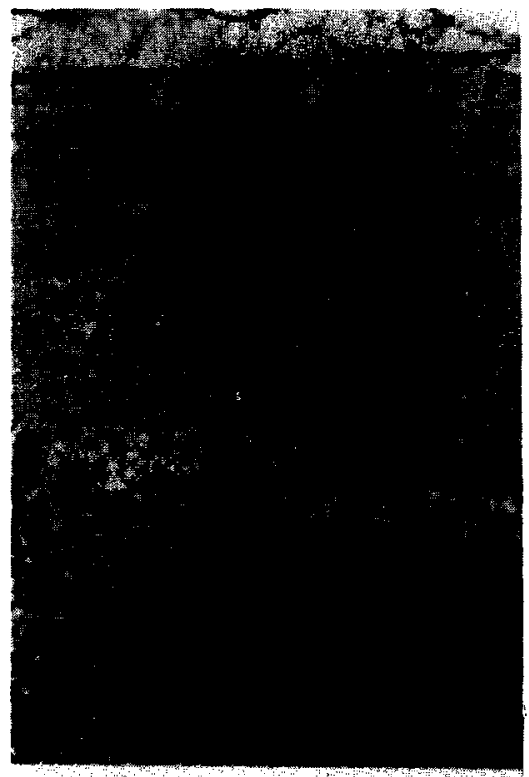

A

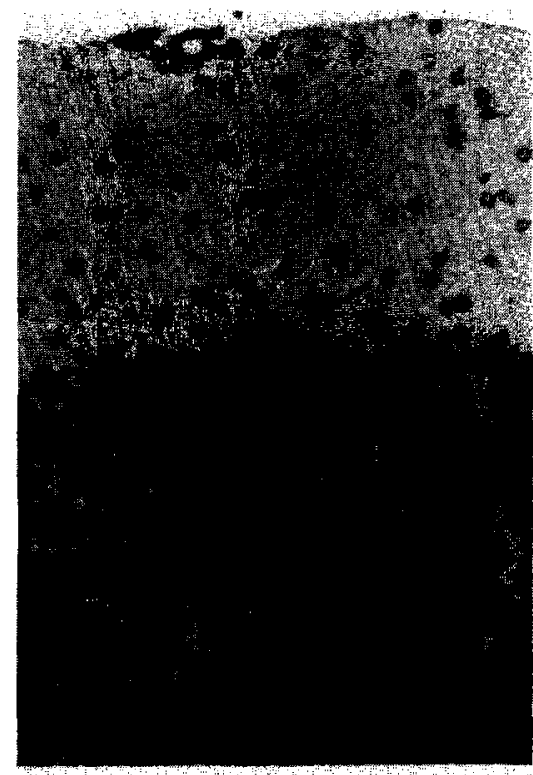

B

Frg. 1. Rat cerebellar cortex; A, incubated for 3 hours in glucose without glycolytic blockers; and B, under the same conditions, but with addition of glycolytic blockers. Hematoxylin and eosin; $190 \times$.

entire granular layer resulting from an excessive edema and ballooning of the perikarya of the granular cells which appeared like groups of vesicles with their nuclei in the center. The synaptic glomerula were nearly normal in size or were slightly compressed, thus resembling the behavior of the Purkinje cells described above. The swelling of the granular cells was most accentuated in the periphery of the specimens which were immediately exposed to the medium. These changes increased with the increase in concentration of glucose-6-phosphate (up to $200 \mathrm{mg} / 100 \mathrm{ml}$ ) and with longer incubation times (up to 4 hours). The $\mathrm{pH}$ drop did not 
exceed that in glucose media. Blocking of glycolysis prevented both tissue changes and the drop of the $\mathrm{pH}$.

A slight swelling of the granular cells was also seen after incubation with glucose; the changes after glucose-6-phosphate, however, were much greater and out of proportion to the changes in the Purkinje layer.

Reliability of Observations. Five specimens each were incubated for 3 hours in glucose $(200 \mathrm{mg} / 100 \mathrm{ml})$, glucose-6-phosphate $(200 \mathrm{mg} / 100$
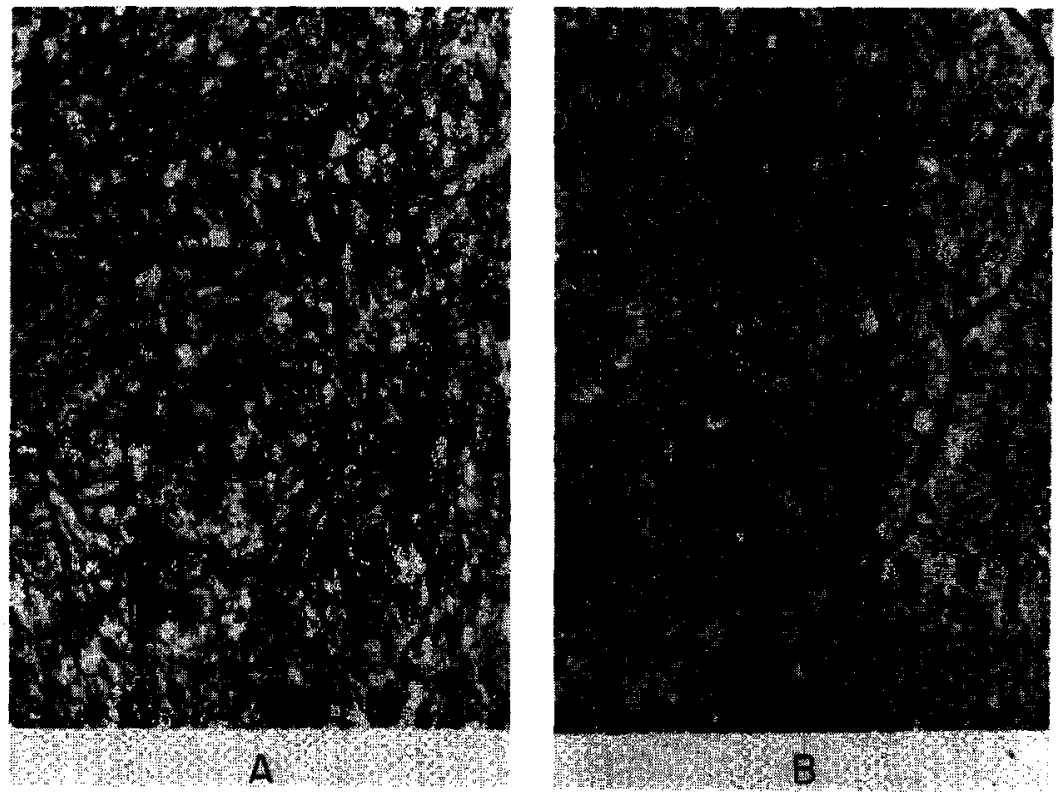

Fig. 2. A, astrocytes in white matter incubated for 3 hours in glucose with blocked glycolysis; B, klasmatodendrosis of astrocytes, incubated as in A, but without glycolytic blocking. Hortega's silver carbonate method; $260 \mathrm{X}$.

$\mathrm{ml}$ ), and glucose with blocking agents. One of us prepared the specimens while the other evaluated the unmarked slides. The types of tissue alterations described above were so typical that the incubation medium was correctly identified in every specimen.

Changes of Astrocytes. Silver stains of the experimental material showed well preserved astrocytes in white matter after 3 hours of incubation, if the glycolysis was blocked (Fig. 2A). In the presence of glycolytic activity there were severe changes of the astrocytes such as klasmatodendrosis. The processes of the astrocytes were shortened and swollen and 
showed a tendency to disintegrate (Fig. 2B), forming small corpuscles (filling bodies). The Bergman neuroglia cells of the cerebellar Purkinje layer could not be studied because silver methods did not demonstrate them. These observations would seem to throw some light on the question of the significance of klasmatodendrosis which has been claimed to be a post-mortem alteration or a pathological change.

Relation of Tissue Changes and Normal Cytochemical Tissue Architecture. The distribution of tissue alterations were compared with the normal distribution of axidative enzyme activity in brain tissue, as described recently in a mapping of succinic dehydrogenase in the guinea pig brain (1) and an atlas of four oxidative enzymes in the cat brain (2). Succinic dehydrogenase, cytochrome oxidase, DPN- and TPN-diaphorase all showed a similar distribution in the cerebellar cortex. The molecular layer showed diffusely distributed enzyme activity in the neuropil in which some large dendrites were distinguishable. The perikarya of the Purkinje cells had strong enzyme activity, but there was little in the aggregations of neuroglia cells between them (Fig. 3A). In the granular layer, oxidative enzymes were confined to the synaptic glomerula cerebellaria; the perikarya of the granular cells lacked oxidative enzymes (2). Additional studies have shown that normal astrocytes (as opposed to hypertrophic ones) generally contained extremely little activity of oxidative enzymes (3).

A comparison of these data with the experimental glycolytic tissue changes showed that the latter were most marked in regions where cells with weak enzymatic activity were aggregated, such as the groups of neuroglia cells between the Purkinje cells.

Searching for other regions with a similar organization, the ventricular walls and the choroid plexus drew attention. Both showed a layer of tissue with weak enzyme activity (subependymal neuroglia cells; plexus stroma), being sharply separated from a lamina of cells with strong enzyme activity (ependyma). If these regions were incubated in the manner described above, an excessive edema of the "low enzyme" structures was found; this edema was prevented by the blocking of glycolysis. Other regions in the brain did not show such contrasting enzyme patterns; if incubated, they would show marked changes of neuroglia cells, but not the extensive distortion of the tissue structure which was found in the Purkinje cells, subependymal neuroglia cells, and plexus-stroma.

Comparison of Experimental and Human Post-Mortem Changes. Comparison of the experimental material with a large amount of human post- 
mortem material did not permit one to distinguish between experimental and post-mortem changes. The regions with maximal experimental alterations were well known as sites of predilection of post-mortem changes in human tissue, such as the laminar separation of the cerebellar cortex (Fig. 3B) or the ablation of the ependyma which are seen frequently in autopsy material.
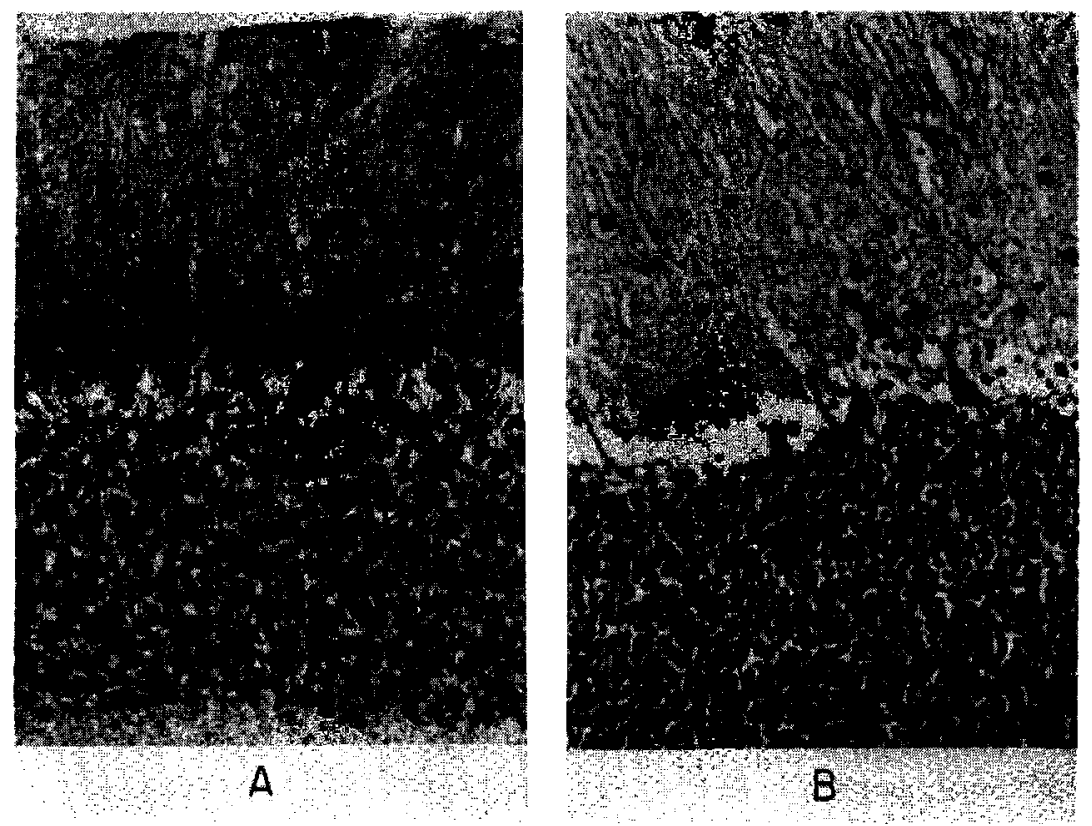

Fic. 3. A, distribution of DPN-diaphorase in the rat cerebellar cortex. Tetrazolium technique by Farber, Sternberg, and Dunlap, using Nitro BT; 30 ; $200 \times$. B, typical post-mortem alterations in human cerebellar cortex. Swollen glia cells at the right, complete separation of the layers at the left. Hematoxylin and eosin; $200 \times$.

\section{Discussion}

The experimental tissue changes evidently resulted from the continuation of anaerobic glycolysis under anoxibiotic conditions. Assays of lactic acid in the incubation media were not done, since the drop of the $\mathrm{pH}$ during incubation in glucose in the presence of cyanide and its prevention by the blocking of glycolysis was considered sufficient indication for the presence of anaerobic glycolysis. Glycolysis was associated with characteristic tissue alterations which were indistinguishable from those ob- 
served in human post-mortem material. Blocking of glycolysis during incubation eliminated these alterations.

There were relations between the normal cytochemical organization of the tissue and the extent of glycolytic tissue changes. Maximal alterations were found where large aggregations of neuroglia cells (or connective tissue) with little activity of oxidative enzymes bordered regions with very strong activity. Anaerobic glycolysis evidently occurred predominantly in the neuroglia cells, particularly the astrocytes, which normally had little oxidative metabolism; these cells showed an edema and klasmatodendrosis. The extent of alterations in neuroglia cells under normal post-mortem conditions probably would depend largely on the carbohydrate reserves in the tissue. This may explain the intriguing observations by Lindenberg and Noell (5) who found excellent preservation of astrocytes in animals exposed to anoxia for at least 1 hour before death in contrast to klasmatodendrosis in normal controls. The anoxia evidently depleted the tissue of its reserves (5), thus producing an effect similar to that of blocking of glycolysis in our material.

Blocking of glycolysis has been utilized in neurohistological studies by Schabadasch (7); however, it will be of limited significance if the brain is fixed as quickly as possible. If there is any delay of fixation, blocking of glycolysis (such as by poisoning of animals with blockers) should be considered as a method for the preservation of the vital tissue structure; this factor will be of particular significance for experimental studies of edema.

The different effects of glucose and glucose-6-phosphate may represent only a quantitative gradient. There is a possibility, on the other hand, that the phosphorylation of glucose and the initial phases of glycolysis might be performed by the neuroglia cells thus offering metabolites rather than glucose to the structures with strong tissue oxidation; blocking of the aerobic metabolism in the latter would throw the system off balance. This might explain why the structures of strong enzyme activity did not swell as much as the neuroglia cells. The cerebellar granular cells apparently utilized glucose-6-phosphate more readily than glucose, while the neuroglia cells did not show such a gradient.

The relationship between post-mortem changes and continuation of anaerobic glycolysis rendered the histological distinction of pathological and post-mortem changes in human material highly questionable: The mechanism of post-mortem tissue changes might likely become effective 
during an impairment of tissue oxidation in life; certain edematous changes and certain post-mortem alterations, thus, might be closely akin.

\section{References}

1. FrIEDE, R. L., Histochemical investigations on succinic dehydrogenase in the central nervous system: II. Atlas of the medulla oblongata of the guinea pig. J. Neurochem. 4: 101-110, 1959.

2. FrIEDE, R. L., "A histochemical atlas of tissue oxidation in the brain stem of the cat." Basel \& New York, Karger, 1961.

3. FRIEDE, R. L., The cytochemistry of normal and reactive astrocytes. J. Neuropathol. Exptl. Neurol. (in press).

4. JungmanN, H., and P. Kimmelstiex, Über den Ursprung der Milchsäure im Zentralnervensystem. Biochem. Z. 212: 347-358, 1929.

5. Lindenberg, R., and W. NoelL, Über die Abhängigkeit der postmortalen Gestalt der Astrocyten von praemortalem, bioelektrisch kontrolliertem Sauerstoffmangel. Deut. Z. Nervenheilk. 168: 499-517, 1952.

6. McGinty, D. A., and R. Geselr, On the chemical regulation of respiration. Am. J. Physiol. 75: 70-83, 1925.

7. Schabadasch, A., Morphology of glycogen distribution and transformations: I. Principles of fixation and staining of glycogen for micro and macroscopic studies. Byull. Eksp. Biol. Med. 4: 13-16, 19.37. 